\title{
Exposure Factors Associated With SARS-CoV-2 Seroprevalence During the First Eight Months of the COVID-19 Pandemic in the Netherlands: A Cross- sectional Study
}

Demi ME Pagen ( $\square$ Demi.Pagen@ggdzl.nl )

South Limburg Public Health Service

\section{Stephanie Brinkhues}

South Limburg Public Health Service

Nicole HTM Dukers-Muijrers

South Limburg Public Health Service

Casper DJ den Heijer

South Limburg Public Health Service

Noortje Bouwmeester-Vincken

North Limburg Public Health Service

\section{Daniëlle AT Hanssen}

Maastricht University Medical Centre (MUMC+), Maastricht University

Inge HM van Loo

Maastricht University Medical Centre (MUMC+), Maastricht University

Paul HM Savelkoul

Maastricht University Medical Centre (MUMC+), Maastricht University

Christian JPA Hoebe

South Limburg Public Health Service

\section{Research Article}

Keywords: COVID-19, SARS-CoV-2, seroprevalence, exposure factors

Posted Date: December 28th, 2021

DOI: https://doi.org/10.21203/rs.3.rs-1159143/v1

License: (영 This work is licensed under a Creative Commons Attribution 4.0 International License. Read Full License 


\section{Abstract}

\section{Background}

The availability of valid SARS-CoV-2 serological tests overcome the problem of underestimated cumulative COVID-19 cases during the first months of the pandemic in The Netherlands. This enabled us to study a wide variety of demographic, behavioural and social exposure factors associated with seropositivity during the first eight months of the pandemic in Limburg, The Netherlands.

\section{Methods}

SARS-CoV-2 point-seroprevalence was determined cross-sectionally to indicate previous infection in a convenience sample of 10,000 inhabitants of the study province. Possible exposure factors were mapped by means of an extensive questionnaire. Associated exposure factors were determined using uni- and multivariable logistic regression models.

\section{Results}

Seropositivity was established in $19.5 \%(n=1,948)$ of the 10,001 participants (on average 49 years old $(S D=15$; range $18-90$ years), majority women $(n=5,829 ; 58.3 \%)$. Exposure factors associated with seropositivity included current education, working in healthcare and not working from home, and being a member of three or four associations or clubs. Specifically for February-March 2020, visiting an après-ski bar during winter sports in Austria, travelling to Spain, celebrating carnival, and participating in a singing activity or ball sport were associated with seropositivity.

\section{Conclusions}

Our results confirm that relevant COVID-19 exposure factors generally reflected circumstances where social distancing was impossible, and the number and duration of contacts was high, in particular for indoor activities.

\section{Introduction}

By November 2021, there have been more than 246 million confirmed coronavirus disease (COVID-19) cases worldwide since the start of the pandemic, accompanied by approximately 5 million COVID-related reported deaths [1]. On 27th February 2020, the first COVID-19 case was confirmed in the Netherlands [2]. Initially, the province of Limburg was one of the most heavily affected Dutch provinces, with 439 confirmed cases per 100,000 inhabitants until July 2020 and the highest hospitalization and mortality rate nationally [3]. Average mortality was exceeded with $62 \%$ for this province during the first nine weeks of the pandemic [4]. Burden continued during the second wave of infections, when the southern provinces remained the most affected areas regarding COVID-related deaths as well [3].

In the Netherlands, the total number of COVID-19 cases was largely underestimated during the first months of the pandemic. Patients were initially only tested for COVID-19 when clinical symptoms were present (i.e. 
fever $\left(\geq 38^{\circ} \mathrm{C}\right)$ and dyspnoea and/or cough) together with an epidemiological link (i.e. contact with a confirmed case or travel to an high COVID-19 incidence area) [5]. This underestimation limited the possibility to assess which factors contributed to the primary spread of severe acute respiratory syndrome coronavirus 2 (SARS-CoV-2).

Numerous activities or circumstances can accelerate virus spread, here defined as exposure factors. Since SARS-CoV-2 can be transmitted directly and by air, social distancing with a minimum of one to two meters is assumed to be sufficient to avoid spreading [6]. Furthermore, air quality and adequate ventilation is key, as shown in an experimental setting where SARS-CoV-2 remained viable in aerosols for the duration of three hours [7]. The application of social distancing and ventilation measures are unequally spread over settings and contexts, such as types of occupation. A significantly increased risk of COVID-19 infection was established among frontline healthcare workers in the United Kingdom [8]. A Norwegian population-based study showed that other healthcare workers (e.g. nurses, physicians, dentists and physiotherapists), people working in hospitality industry and in (public) transport also had a higher odds of a COVID-19 infection confirmed by positive polymerase chain reaction (PCR) during the first two waves of infection [9].

Just before infection prevention measures were implemented in March 2020, many mass events such as the annual carnival celebrations took place (Figure 1). Subsequent interdiction of mass events by the implemented measures, challenged the opportunity to measure their contribution to virus spreading at later times.

To better understand initial drivers for exposure risk in the absence of routine testing at that time, serology can be used to identify (unnoticed) infections. Serological testing in an unvaccinated population allows to reliably determine the number of truly infected persons. In $92 \%$ of the cases, COVID-19 antibodies are still detectable seven months after infection [10]. Hence, our study aimed to evaluate seroprevalence exposure factors associated with seropositivity during the first eight months of the pandemic, assessed prior to vaccination. Determining these exposure factors that facilitate transmission can be useful to inform future infection prevention policies and potentially confirm the effectiveness of existing measures.

\section{Method}

\section{Study design}

A cross-sectional study was designed to assess exposure factors which contributed to the spread of SARSCoV-2 in the first eight months of the pandemic. A convenience sample of 10,000 inhabitants of a southern Dutch province was used, reflecting about $1 \%$ of 1 million adults in this province. Point-seroprevalence was determined to indicate previous infection. Possible exposure factors were mapped by means of an extensive questionnaire. A convenience sample was chosen to accommodate equal opportunities for the general population in their great demand on to know about their COVID-19 serostatus.

\section{Participants}


All adult inhabitants of 18 years and older of our study province (Limburg) were eligible for participation until sufficient registrations were reached. Participants needed to speak, read, and write Dutch language, as the questionnaire was only available in Dutch. This applies to $95 \%$ of our study province inhabitants [11].

\section{Data collection}

Data collection was completed between $28^{\text {th }}$ October and $23^{\text {rd }}$ December 2020 and comprised donating a blood sample and filling out an online questionnaire.

Online participation registration was conducted via market research software from Crowdtech (ISO-20252 and ISO-27001 certified, London, UK). To register, personal and contact details were required. An appointment for blood drawing was made by phone at one of the four test locations (Maastricht, Urmond, Landgraaf, and Venlo). One $10 \mathrm{ml}$ EDTA tube was taken by venepuncture by trained and certified health professionals. All blood samples were kept at room temperature and transported to the Medical Microbiology Laboratory of the Maastricht University Medical Centre+ (MUMC+). Samples were tested for total COVID-19 antibodies using the Wantai SARS-CoV-2 Ab ELISA test (Beijing Wantai Biological Pharmacy Enterprise Co., Ltd., Beijing, China) in accordance with the manufacturer's instructions [12]. This test was chosen after showing best performance in a multicentre evaluation by the National Institute for Health and Environment [13]. Samples were classified by optical density value as being positive, borderline, or negative. In our study, eight samples had borderline values. Based on pilot experience using the Wantai among five hospital employees with serum pairs, four out of five borderline values seroconverted to positive in a second serum sample. Therefore, we decided to classify the borderline values as positives. Participants were informed about their serostatus via email within three weeks after providing the blood sample.

\section{Exposure measures}

The online questionnaire was sent by email at least two days after providing the blood sample. The questionnaire covered: general demographics, current education, occupation and opportunity to work from home, memberships to associations or clubs, and specific behaviours performed during the first months (February-March 2020) of the pandemic.

Demographics included gender, age, place of residence and level of education. Level of education was categorized into practically trained (no, lower general, lower vocational, general secondary, and secondary vocational education) and theoretically trained (higher general, pre-university, higher professional, and scientific education). Based on place of residence, two geographical regions of the study province were established: northern and southern. A variety of occupations was listed, such as healthcare, education, daycare, and catering industry. Working in healthcare was further defined by specific sectors. The degree of working from home was determined for different time periods: February-March, April-May, and JuneNovember 2020. Working from home was dichotomized into not working from home during all periods and (partly) working from home during at least one of the periods. Membership to a variety of associations or clubs was assessed and being member to a music association was further specified. Memberships to multiple associations or clubs with a perceived higher risk of infection were merged, including membership to a sport, youth, volunteer, social or traditional association of the study province and a fanfare, brass or jazz 
band were summed up. To grasp all singing activities together as an exposure factor we combined being member of a choral society, a (church)choir or participated in a singing activity. Specific behaviours performed in February-March 2020 comprised travelling for winter sports or other purposes, celebrating carnival, and attending specific activities. For travelling, country of destination was specified supplemented with extent to which participants visited an après-ski bar when travelled for winters sport (i.e., not, couple of days, or majority of the days). For all carnival days separately the amount of time spend inside was counted. A sum score was calculated for attending carnival celebrations inside for all carnival days combined. The score was divided in four categories based on quartiles. Eventually, involvement in 48 different activities where at least 30 people were present was counted. Activities were categorized in religious ceremonies, attractions, events, cultural activities, hobbies, sports, going out, and others. For nine activities the specific date and place of the activity were indicated (attending a wedding or funeral, visiting a museum, convention, charity event, festival, sport event, professional soccer match, or taking a day trip by bus or boat). A telephone helpline was available to facilitate assistance for participants who were unable to fill out the questionnaire themselves.

\section{Statistical analysis}

Only complete participation was taken into analysis, meaning participation with both a blood sample and questionnaire. No missing data had to be handled, since all questions in the questionnaire were mandatory.

Seroprevalence was a dichotomous outcome measure (positive or negative). Seroprevalence was used to identify possible exposure factors, meaning factors where proportion of seropositive participants exceeded the average. Univariable and corrected multivariable logistic regression analysis were used to study the association between possible exposure factors and seropositivity. Exposure factors with a p-value $<0.05$ in univariable logistic regression were retained in the multivariable model and multicollinearity between exposure factors was checked. Interactions between exposure factors and geographical region were tested. No geographical differences in exposure factors were established. A p-value of $<0.05$ was considered statistically significant. Data were analysed using SPSS (version 26.0, IBM, Armonk, USA).

\section{Ethical statement}

The study protocol, participant information form and written informed consent form were reviewed and approved by the Medical Ethical Committee of the MUMC+ (NL74791.068.20/METC20-071). The study is registered at the Netherlands Trial Register (NL8889).

\section{Results}

In total 10,108 participants provided a blood sample and 10,001 participants additionally completed the questionnaire, which was taken as the study population (Figure 2). Main reasons for declining participation included: changed their mind, did not show during appointment, unable to reach, and current COVID-19 infection. 
About $1 \%$ of the adult inhabitants of all 42 municipalities in the study province participated: ranging from $0.2 \%$ to $1.5 \%$ within the various municipalities. The age distribution of participants was comparable to the source population, but the study population included relatively more women; $58.3 \%$ versus $50.3 \%$ in the source population.

\section{Sociodemographic characteristics of the study population}

Participants were on average 49 years of age (standard deviation (SD): 15 , range 18-90) and $52.3 \%$ of the participants were theoretically trained. A considerable number of participants worked in healthcare (Table 1). Some participants $(n=286)$ were aware of their prior COVID-19 infection, PCR confirmed.

\section{Seroprevalence}

Overall, 1,948 of the 10,001 participants tested positive for presence of COVID-19 antibodies (19.5\% [95\% Cl:18.7\%-20.3\%]). Seroprevalence varied geographically and was higher in the northern part $(23.5 \%$ [95\% $\mathrm{Cl}: 22.2 \%-24.9 \%])$ than the southern part (17.0\% [95\% Cl:16.0\%-17.9\%]). A difference in seroprevalence was observed between men (18.7\% [95\% Cl:17.5\%-19.9\%]) and women (20.7\% [95\% Cl:19.0\%-21.0\%]). A relatively high seroprevalence was observed among participants aged between 18 and 29 years of age $(22.8 \%$ [95\% Cl:20.4\%-25.1\%]) and practically trained participants (20.6\% [95\% Cl:19.5\%-21.8\%]) (Table 1).

\section{Exposure factors associated with seropositivity (Table 2)}

Participants following vocational secondary education or scientific education had an increased odds for testing seropositive (OR=1.88 [95\% Cl:1.10-3.23] and 1.60 [95\% Cl:1.14-2.25], respectively).

The odds of seropositivity was 1.55 [95\% Cl:1.37-1.76] for participants working in healthcare versus participants not working in healthcare. The odds were notably higher in disability care (OR=4.17 [95\% $\mathrm{Cl}: 2.68-6.49])$. Overall, not working from home was associated with an increased odds in all healthcare sectors.

Participants being a member of three or four associations or clubs (listed in methods section) were more likely to have COVID-19 antibodies (OR=1.82 [95\% Cl:1.22-2.72]. Singing activities also increased odds of seropositivity (OR=1.65 [95\% Cl:1.30-2.08]).

\section{Specific factors for February-March 2020}

Visiting an après-ski bar for the majority of the days during winter sports in Austria was associated with increased odds for seropositivity ( $\mathrm{OR}=2.49$ [95\% Cl:1.88-3.29]). In addition, traveling to Spain was established to be associated (OR=1.41 [95\% Cl:1.06, 1.87]).

Carnival celebrations while spending more than eight hours inside was positively associated with seropositivity ( $O R_{\text {between }} 8$ and 18 hours $=1.19$ [95\% Cl:1.02-1.40] and $\mathrm{OR}$ more than 18 hours $=1.24$ [95\% Cl:1.041.47]. 
Of the various other activities evaluated, the following increased odds for seropositivity: attended a funeral, played a wind instrument in interplay, visited a sport event (except soccer game), practiced gymnastics, practiced a ball sport (except soccer), visited a bar, café, club, or disco, went out for dinner, and took a day trip by bus or boat.

Practicing a ball sport (except soccer) was associated with seropositivity in the multivariate model $(\mathrm{OR}=1.90$ [95\% Cl:1.36-2.65]).

Notable activities with insufficient participants

An exceptionally high seroprevalence appeared among the participants who attended a charity event in Kessel, a small village in the middle of the study province, which was more than four times the average seroprevalence. Only 15 participants attended this event, making this result sensitive to bias. Two other specific events, namely visiting professional soccer matches in Maastricht, resulted in seroprevalences up to twice the average. Likewise, the number of participants was too small for these events.

\section{Discussion}

In this cross-sectional study evaluating the seroprevalence and extensive questionnaire data from 10,000 inhabitants of a southern Dutch province, the seroprevalence was almost $20 \%$ by the end of 2020 . Several exposure factors were independently associated with seropositivity: following secondary vocational or scientific education, working in healthcare and not working from home, and being a member of three or four associations or clubs. Specifically, for the months of February-March 2020, relevant exposure factors included visiting an après-ski bar in Austria for the majority of the days during winter sports, travelling to Spain, celebrating carnival for longer than eight hours inside, participating in a singing activity, and practicing a ball sport. The majority of the independently associated exposure factors established in our study reflect circumstances where social distancing is probably not generally maintained. Moreover, circumstances where participants are thought to have a high contact rate and activities performed inside show clear associations with seropositivity.

The fact that the initial strict Dutch testing policy greatly underestimated cumulative infections, is highlighted by the results of our study. Until $1^{\text {st }}$ December 2020, in total 25,592 PCR confirmed COVID-19 cases were reported among 1.12 million inhabitants of the study province, reflecting $2.3 \%$ of all inhabitants [3]. The seroprevalence calculated in our study is almost ten times higher compared to the PCR confirmed COVID-19 cases since $27^{\text {th }}$ February 2020 in the study province (2.3\% versus $19.5 \%$ ).

Other Dutch seroprevalence studies established seroprevalences between $11 \%$ and $12 \%$ in healthy plasma donors in November 2020, and between $5 \%$ and $10 \%$ in a representative sample of Dutch inhabitants in September $2020[14,15]$. Overall, our study established the highest seroprevalence in the study province. However, it should be considered that due to the convenience sample, there is a possibility that people who expected to have had an COVID-19 infection were more likely to participate. This could result in a slight overestimation of the seroprevalence in our study. 
The effect of not maintaining social distancing can be seen in occupational settings. Working in healthcare often requires direct patient contact which makes social distancing impossible. Several studies have identified an increased risk of COVID-19 infection in healthcare $[8,9,15]$. The possibility of encountering an infected patient is high among healthcare workers, as severely ill patients are admitted to healthcare facilities to receive required treatment [16].

In addition to the nature of a specific occupation itself, the possibility of working from home diminishes occupational exposure risk. A large Dutch cross-sectional population-based study supports this, by showing 0.71 times lower odds of seropositivity among participants working from home compared to participants not working from home, independent of work sector. The reason for the decreased risk may be partly the result of reduced daily physical contact with colleagues or clients. Seroprevalence was namely also 0.61 times lower among participants without physical contact with patients or clients in their professional or voluntary work [15].

Social distancing is closely related to the contact rate. A reduction of $71 \%$ in the average number of community contacts was observed, since social distancing measures were implemented in the Netherlands [17]. Circumstances where participants were thought to have a great contact rate showed a higher seroprevalence in our study, including being a member of three or four clubs or associations. Attending social meetings equals more varying social contacts, in turn increasing the possibility of getting in contact with a COVID-19 infected person. This is supported by a previous study examining the association between network parameters and several self-reported infections [18]. Among 3,004 Dutch participants aged 60 years on average, network size was significantly associated with upper respiratory tract and gastrointestinal infection. For every additional $10 \%$ of acquaintance contacts, including club mates, the odds of lower respiratory tract infection increased by $4 \%$. However, this study did not show a significant association between number of club memberships and any of the above-mentioned infections.

The probability of virus transmission in a contact is partly determined by the stability of the virus in the environment, which is greater in circumstances with insufficient ventilation. Spending time inside, for example celebrating carnival or going to an après-ski bar during winter sports, shows a clear association with seropositivity in our study. One comparable study regarding spending time inside was carried out among 1,120 Danish medical students. Students who attended one or two parties organized before lockdown happened demonstrated a sixfold increase of seropositivity [19]. These findings highlight that an indoor environment is favourable for SARS-CoV-2 transmission. Nevertheless, no significant association was established between visiting a regular bar, café, or disco and seropositivity in our study. This might be explained by the large proportion of participants that undertook this type of activity, leading to an approximate even distribution between seropositive and seronegative participants. As this activity is not very specific, the association might be faded by other more pronounced activities and circumstances. Moreover, the counted visits to a bar, café, or disco not related to the carnival celebrations were in all probability before COVID-19 was widely spread in the study province. Therefore, there is a lower chance of getting infected during this kind of visit. Subsequently, implementation of infection prevention measures totally prohibited visiting these facilities, thereby eliminating exposure risk in this setting. 
Furthermore, the impact of effortless travel nowadays should not be underestimated. According to an American mathematical modelling study, unconstrained mobility would have significantly accelerated the spread of SARS-CoV-2, especially in Central Europe, Spain and France [20]. The significant associations with travel destinations determined in our study support this.

To the best of our knowledge, this is the first large scale study examining an extensive diversity of possible demographic, social and behavioural risk factors for SARS-CoV-2 seropositivity. The questionnaire mapped many exposure factors and gave rise to the possibility to correct analyses for relevant characteristics. Regarding the validity of the serological test used in our study, a nationwide multicentre evaluation study indicated high sensitivity (97.5\% after severe infection and $95.4 \%$ after mild infection) and high specificity of $99.6 \%$, using PCR as reference [13]. Solely serology could be used to estimate cumulative infections, as initially a strict testing policy was maintained in the Netherlands. All tests were performed in the same laboratory, limiting differences in processing and execution of the tests, making results well comparable.

Our study had some limitations as well. First, selection bias cannot be ruled out due to the convenience sampling. However, sampling methods including a random sample can be subjected to substantial nonresponse, resulting in bias as well. The yielded study population in our study is quite representative regarding geographical and age distribution. Considering we were interested in exposure factors, the generalizability of the determined seroprevalence was less relevant. Second, recall bias could have occurred since participating in specific activities was listed for a period up to eight months earlier. Associations can be underestimated when participants did not remember their attendance at a specific event. In the study design, we attempted to limit recall bias by encouraging participants to use their agenda when filling out the questionnaire. Completing the questionnaire at home diminished time pressure and lowered possible recall bias as well. Third, associations between exposure factors at the beginning of the pandemic and seropositivity might be attenuated, due to the possible long period between the exposure and serology testing. Related to this, the overall multivariate model has a low $\mathrm{R}^{2}$ of $3.2 \%$, meaning that a small part the variance in the data can be explained by the final model. This indicates that there are many more factors that contributed. From source and contact tracing activities we know that many infections occur, for instance, at home or during contacts with friends. In an eight-month period, there are innumerable activities and circumstances where an infection can be acquired. Nevertheless, exposure factors that took place before the official first COVID-19 cases, for example the carnival celebrations, were still independently associated, implying that these factors have substantially contributed to the primary spread of the virus.

In conclusion, the strict Dutch testing policy resulted in a great underestimation of cumulative COVID-19 infections during the first wave. Our results confirm that relevant COVID-19 exposure factors generally reflect circumstances where social distancing was impossible, and the number and duration of contacts was high, in particular for indoor activities (without proper ventilation). The measures taken at the beginning of the pandemic accurately targeted these circumstances to contain virus transmission.

Moreover, our results can have an added value in responsibly relaxing infection prevention measures and reopening society, as they can help to prioritize which activities should be addressed as high COVID-19 risk. 
Subsequently, the risk of exponential spreading can be managed when allowing these 'high risk' activities again.

\section{Abbreviations}

Cl: Confidence Interval

COVID-19: Coronavirus Disease 2019

EDTA: Ethylenediaminetetraacetic Acid

ELISA: Enzyme-Linked Immunosorbent Assay

MUMC+: Maastricht University Medical Center+

OR: Odds Ratio

PCR: Polymerase Chain Reaction

SARS-CoV-2: Severe Acute Respiratory Syndrome Coronavirus 2

SD: Standard Deviation

SP: Seroprevalence

SPSS: Statistical Package for the Social Sciences

\section{Declarations}

\section{Ethics approval and consent to participate}

Ethical approval was obtained by the Medical Ethical Committee of the MUMC+ (NL74791.068.20/METC20071). The study is registered at the Netherlands Trial Register (NL8889). Written informed consent was obtained from all participants, and the study was conducted according to the principles set by the Declaration of Helsinki and the Medical Research Involving Human Subjects Act (WMO).

\section{Consent for publication}

Not applicable.

\section{Availability of data and materials}

The datasets used and/or analysed during the current study are available from the corresponding author on reasonable request.

\section{Competing interests}


The authors declare that they have no competing interests.

\section{Funding}

This work was financially supported by the Province of Limburg, the Netherlands. The funding provider had no role in the study design, the collection, analysis and interpretation of the data, nor in writing the manuscript.

\section{Authors' contributions}

DP, SB, ND, NB-V, IVL, DH, CH designed the study. DP, SB, DH actively participated in data collection. DP performed the data analysis and wrote the first draft of the manuscript. SB, ND, CdH, CH supervised data analysis and data collection. All authors were involved in data interpretation, revised the manuscript critically for important intellectual content, approved the final version, and agreed to be accountable for all aspects of the manuscript.

\section{Acknowledgements}

We gratefully acknowledge CJD Goense and LCJ Steijvers for their valuable contribution to the development of the questionnaire, and the technicians of the Department of Medical Microbiology subdivision serology of the MUMC+.

\section{References}

1. WHO Coronavirus (COVID-19) Dashboard. Available at: https://covid19.who.int/. Accessed 3-11-2021.

2. Alderweireld CEA, Buiting AGM, Murk J-LAN, Verweij JJ, Berrevoets MAH, van Kasteren MEE. COVID-19: patiënt nul in Nederland. Nederlandse tijdschrift voor geneeskunde 2020.

3. Epidemiologische situatie COVID-19 in Nederland: Rijksinstituut voor Volksgezondheid en Milieu (RIVM), 2020.

4. In welke provincie overleden meer mensen dan verwacht? Available at: https://www.cbs.nl/nl$\mathrm{nl} / \mathrm{faq} /$ corona/regionaal/in-welke-provincie-overleden-meer-mensen-dan-verwacht-. Accessed 8 July 2021.

5. Advies n.a.v. OMT 2019-nCoV (Wuhan): Rijksinstituut voor Volksgezondheid en Milieu (RIVM), 2020.

6. Borak J. Airborne transmission of COVID-19: Oxford University Press UK, 2020.

7. Van Doremalen N, Bushmaker T, Morris DH, et al. Aerosol and surface stability of SARS-CoV-2 as compared with SARS-CoV-1. New England journal of medicine 2020; 382:1564-7.

8. Nguyen LH, Drew DA, Joshi AD, et al. Risk of COVID-19 among frontline healthcare workers. MedRxiv 2020.

9. Magnusson K, Nygard KM, Methi F, Vold L, Telle KE. Occupational risk of COVID-19 in the 1st vs 2nd wave of infection. medRxiv 2021:2020.10. 29.20220426.

10. den Hartog G, Vos ER, van den Hoogen LL, et al. Persistence of antibodies to SARS-CoV-2 in relation to symptoms in a nationwide prospective study. Clinical Infectious Diseases 2021. 
11. Kwart 15-plussers spreekt thuis dialect of andere taal dan Nederlands. Available at: https://www.cbs.nl/nl-nl/nieuws/2021/28/kwart-15-plussers-spreekt-thuis-dialect-of-andere-taal-dannederlands.

12. Beijing Wantai Biological Pharmacy Enterprise Co. L. WANTAI SARS-CoV-2 Ab ELISA. Available at: https://www.dbaitalia.it/newsletter/sars-cov-2_ab_elisa_v1-ce_ifu.pdf. Accessed 22-7-2021.

13. van den Beld MJ, Murk J-L, Kluytmans J, et al. Increasing the Efficiency of a National Laboratory Response to COVID-19: a Nationwide Multicenter Evaluation of 47 Commercial SARS-CoV-2 Immunoassays by 41 Laboratories. Journal of Clinical Microbiology 2021; 59:e00767-21.

14. Slot E, Hogema BM, Zaaijer HL. Antistoffen tegen coronavirus begin januari bij $13 \%$ van de donors. Available at: https://www.sanquin.nl/over-sanquin/nieuws/2021/01/antistoffen-tegen-coronavirus-bij13-procent-van-de-donors-januari-2021. Accessed 20-7-2021.

15. Vos ERA, van Boven M, den Hartog G, et al. Associations between measures of social distancing and SARS-CoV-2 seropositivity: a nationwide population-based study in the Netherlands. Clinical Infectious Diseases 2021.

16. Koh D. Occupational risks for COVID-19 infection. Occupational Medicine (Oxford, England) 2020; 70:3.

17. Backer JA, Mollema L, Vos ER, et al. Impact of physical distancing measures against COVID-19 on contacts and mixing patterns: repeated cross-sectional surveys, the Netherlands, 2016-17, April 2020 and June 2020. Eurosurveillance 2021; 26:2000994.

18. Brinkhues S, Schram MT, Hoebe CJPA, et al. Social networks in relation to self-reported symptomatic infections in individuals aged 40-75 - the Maastricht study -. BMC Infectious Diseases 2018; 18:300.

19. Madsen JR, Nielsen JP, Fogh K, et al. Anti-SARS-CoV-2 seropositivity among medical students in Copenhagen. medRxiv 2021.

20. Linka K, Peirlinck M, Sahli Costabal F, Kuhl E. Outbreak dynamics of COVID-19 in Europe and the effect of travel restrictions. Computer Methods in Biomechanics and Biomedical Engineering 2020; 23:710-7.

\section{Tables}

Table 1. Characteristics of total study population $(n=10,001)$ and stratified for serostatus 
Total $n=10,001$

\begin{tabular}{|c|c|c|c|c|c|c|c|c|}
\hline & & & & & $n=8,053$ & & $n=1,948$ & \\
\hline Gender & SP (\%) & $95 \% \mathrm{Cl}$ & $\mathrm{n}$ & $\%$ & $\mathrm{n}$ & $\%$ & $\mathrm{~N}$ & $\%$ \\
\hline Male & 18.7 & $17.5-19.9$ & 4,167 & 41.7 & 3,389 & 42.1 & 778 & 39.9 \\
\hline Female & 20.0 & 19.0-21.0 & 5,829 & 58.3 & 4,662 & 57.9 & 1,167 & 59.9 \\
\hline Other & - & & 5 & 0 & 2 & 0 & 3 & 0.2 \\
\hline Age (mean (SD)) & - & & $49(15)$ & & $49(15)$ & & $50(15)$ & \\
\hline Age & & & & & & & & \\
\hline $18-29$ years & 22.8 & $20.4-25.1$ & 1,208 & 12.1 & 933 & 11.6 & 275 & 14.1 \\
\hline $30-39$ years & 16.5 & $14.7-18.2$ & 1,676 & 16.8 & 1,400 & 17.4 & 276 & 14.2 \\
\hline $40-49$ years & 16.9 & $15.2-18.7$ & 1,766 & 17.7 & 1,467 & 18.2 & 299 & 15.3 \\
\hline $50-59$ years & 21.0 & $19.4-22.7$ & 2,393 & 23.9 & 1,890 & 23.5 & 503 & 25.8 \\
\hline $60-69$ years & 20.3 & $18.6-22.0$ & 2,163 & 21.6 & 1,723 & 21.4 & 440 & 20.3 \\
\hline 70-79 years & 19.4 & $16.6-22.3$ & 746 & 7.5 & 601 & 7.5 & 145 & 7.4 \\
\hline $80+$ years & 20.8 & $9.3-32.3$ & 49 & 0.5 & 39 & 0.5 & 10 & 0.5 \\
\hline Geography & & & & & & & & \\
\hline Northern part & 23.6 & $22.7-24.4$ & 3,770 & 37.7 & 2,882 & 35.8 & 888 & 45.6 \\
\hline Southern part & 17.0 & $16.3-17.7$ & 6,231 & 62.3 & 5,171 & 64.2 & 1,060 & 54.4 \\
\hline Level of education & & & & & & & & \\
\hline Practically trained & 20.6 & $19.5-21.8$ & 4,768 & 47.7 & 3,784 & 47.0 & 984 & 50.5 \\
\hline Theoretically trained & 18.4 & $17.4-19.4$ & 5,233 & 52.3 & 4,269 & 53.0 & 964 & 49.5 \\
\hline Occupation & & & & & & & & \\
\hline Healthcare & 25.8 & $23.6-27.9$ & 1,567 & 15.7 & 1,163 & 14.4 & 404 & 20.7 \\
\hline Catering industry & 23.8 & $18.7-28.9$ & 269 & 2.7 & 205 & 2.5 & 64 & 3.3 \\
\hline Non-medical service & 22.1 & $15.5-28.6$ & 154 & 1.5 & 120 & 1.5 & 34 & 1.7 \\
\hline Youth care & 18.8 & $12.8-24.7$ & 165 & 1.6 & 134 & 1.7 & 31 & 1.6 \\
\hline Education & 18.5 & $15.5-21.5$ & 644 & 6.4 & 525 & 6.5 & 119 & 6.1 \\
\hline Day-care & 18.3 & $11.1-25.6$ & 109 & 1.1 & 89 & 1.1 & 20 & 1.0 \\
\hline Retail & 18.7 & $14.7-22.6$ & 375 & 3.7 & 305 & 3.8 & 70 & 3.6 \\
\hline Other transport and storage & 23.7 & $16.7-30.8$ & 139 & 1.4 & 106 & 1.3 & 33 & 1.7 \\
\hline
\end{tabular}




\begin{tabular}{|c|c|c|c|c|c|c|c|c|}
\hline Administration & 20.1 & $17.1-23.0$ & 693 & 6.9 & 554 & 6.9 & 139 & 7.1 \\
\hline Knowledge work & 16.3 & $13.8-18.8$ & 830 & 8.3 & 695 & 8.6 & 135 & 6.9 \\
\hline Technical & 19.1 & $16.4-21.8$ & 801 & 8.0 & 648 & 8.0 & 153 & 7.9 \\
\hline Government & 17.6 & $14.9-20.3$ & 766 & 7.7 & 631 & 7.8 & 135 & 6.9 \\
\hline Emergency services ${ }^{a}$ & 10.4 & $5.3-15.6$ & 134 & 1.3 & 120 & 1.5 & 14 & 0.7 \\
\hline Media and communication & 11.9 & 7.5-16.3 & 210 & 2.1 & 185 & 2.3 & 25 & 1.3 \\
\hline Other ${ }^{b}$ & 17.3 & $15.9-18.7$ & 318 & 3.2 & 263 & 3.3 & 55 & 2.8 \\
\hline Not working & 18.3 & $14.1-22.5$ & 2,827 & 28.3 & 2,310 & 28.7 & 517 & 26.5 \\
\hline \multicolumn{9}{|l|}{ Type of healthcare facility } \\
\hline Disabled care & 37.1 & $29.8-44.4$ & 167 & 1.7 & 105 & 1.3 & 62 & 3.2 \\
\hline Home care & 26.6 & 19.3-33.9 & 139 & 1.4 & 102 & 1.3 & 37 & 1.9 \\
\hline Nursing home & 31.1 & $24.0-38.2$ & 163 & 1.6 & 112 & 1.4 & 51 & 2.6 \\
\hline Hospital & 26.5 & $20.8-32.2$ & 234 & 2.3 & 172 & 2.1 & 62 & 3.2 \\
\hline Other ${ }^{c}$ & 22.2 & $19.4-25.0$ & 864 & 8.6 & 672 & 8.3 & 192 & 9.8 \\
\hline Not working in healthcare & 18.3 & $17.5-19.1$ & 8,434 & 84.3 & 6,890 & 85.6 & 1,544 & 79.3 \\
\hline
\end{tabular}

Note.- $\mathrm{Cl}$, confidence intervals; SD, standard deviation; SP, seroprevalence.

${ }^{\text {a }}$ Excluding ambulance service.

${ }^{b}$ Process industry, agriculture and horticulture, public transport, transport of fuels and waste or other.

${ }^{\mathrm{c}}$ Ambulance service, physiotherapy and occupational therapy, intramural and extramural mental healthcare, general practice, youth care, maternity care or obstetric practice, rehabilitation clinic, dental practice, small scale housing, residential care institution or other.

Values are $\mathrm{n}(\%)$ unless otherwise specified. Seroprevalence represents the proportion of seropositive participants in the total study population. Percentages per category are presented for total study population, seronegative and seropositive populations.

\section{Table 2. Exposure factors associated with SARS-CoV-2 seroprevalence stratified for univariable and multivariable logistic regression models}

\section{Figures}


Univariable

Multivariable

\begin{tabular}{|c|c|c|c|c|c|c|c|c|}
\hline Gender & $\mathrm{N}$ & $\begin{array}{l}\text { SP } \\
(\%)\end{array}$ & OR & $95 \% \mathrm{Cl}$ & $\begin{array}{l}\mathrm{p} \\
\text { value }\end{array}$ & OR & $95 \% \mathrm{Cl}$ & $\begin{array}{l}\mathrm{p} \\
\text { value }\end{array}$ \\
\hline Male (ref.) & 4,167 & 18.7 & - & - & 0.043 & - & - & 0.064 \\
\hline Female & 5,829 & 20.0 & 1.08 & $0.98-01.20$ & 0.126 & 1.04 & $0.93-1.16$ & 0.490 \\
\hline Other & 5 & - & - & - & - & - & - & - \\
\hline Age (years) & 10,001 & - & 1.00 & $1.00-1.00$ & 0.748 & 1.01 & $1.00-1.01$ & $<0.001$ \\
\hline \multicolumn{9}{|l|}{ Current education } \\
\hline No (ref.) & 9,309 & 19.1 & - & - & 0.001 & - & - & 0.008 \\
\hline $\begin{array}{l}\text { Other/unknown } \\
\text { education }\end{array}$ & 140 & 17.1 & 0.88 & $0.56-1.36$ & 0.555 & 0.92 & $0.58-1.45$ & 0.718 \\
\hline Secondary school & 39 & 28.2 & 1.66 & $0.83-3.34$ & 0.155 & 1.93 & $0.94-3.96$ & 0.074 \\
\hline $\begin{array}{l}\text { Secondary } \\
\text { vocational } \\
\text { education }\end{array}$ & 66 & 33.3 & 2.11 & $1.26-3.54$ & 0.004 & 1.88 & $1.10-3.23$ & 0.022 \\
\hline $\begin{array}{l}\text { Higher } \\
\text { professional } \\
\text { education }\end{array}$ & 232 & 23.3 & 1.28 & $0.94-1.75$ & 0.114 & 1.27 & $0.91-1.78$ & 0.165 \\
\hline $\begin{array}{l}\text { Scientific } \\
\text { education }\end{array}$ & 215 & 26.5 & 1.53 & $1.12-2.07$ & 0.007 & 1.60 & $1.14-2.25$ & 0.007 \\
\hline
\end{tabular}

Practically trained $\quad 4,768 \quad 20.6$ (ref.)

Theoretically trained

$\begin{array}{lll}5,233 & 18.4 \quad 0.87\end{array}$

$0.79-0.96$

0.005

$0.90 \quad 0.81-1.00$

0.058

Geography

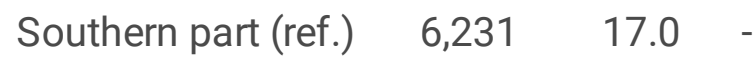

Northern part

$3,770 \quad 23.6 \quad 1.50 \quad 1.36-1.66$

$<0.001 \quad 1.44 \quad 1.30-1.60$

$<0.001$

Work sector

Other (ref.)

8,165

18.1

$<0.001$

$<0.001$

$\begin{array}{lllllllll}\text { Healthcare other }- & 500 & 19.0 & 1.06 & 0.84-1.33 & 0.623 & 1.21 & 0.96-1.54 & 0.113\end{array}$ (partly) worked

from home

Healthcare other -

364

$26.6 \quad 1.64 \quad 1.29-2.08$

$<0.001 \quad 1.72 \quad 1.34-2.20$

$<0.001$ not worked form home

Disability care -

0.163

1.37

$0.81-2.29$

0.239 
(partly) worked

from home

Disability care - not

84

$\begin{array}{llll}50.0 & 4.52 & 2.93-6.95 & <0.001\end{array}$

$4.17 \quad 2.68-6.49$

$<0.001$

worked from home

Home care -

(partly) worked

41

$22.0 \quad 1.27 \quad 0.61-2.67$

0.527

$1.35 \quad 0.64-2.87$

0.432

from home

Home care - not

worked from home

Nursing home care $\quad 61$

- (partly worked

from home)

Nursing home care 102

- not worked from

home

Hospital care -

(partly) worked

113

$23.8 \quad 1.49$

$32.4 \quad 2.16$

$28.6 \quad 1.81 \quad 1.16-2.81$

0.009

$1.70 \quad 1.08-2.69$

0.022

61

$29.5 \quad 1.89 \quad 1.09-3.29$

0.024

2.01

$1.14-3.52$

0.015

from home

Hospital care - not

worked from home

Catering - (partly)

worked from home

Catering - not

worked from home

Member

association/club

No member (ref.)

Member of one

association/club

Member of two

associations/clubs

Member of

three/four

121

$28.1 \quad 1.77 \quad 1.18-2.63$

$\mathbf{0 . 0 0 5} 1.75 \quad 1.16-2.62$

182

$23.6 \quad 1.40$

87

$24.1 \quad 1.44 \quad 0.88-2.36$

$0.99-1.98$

0.059

0.071

$1.58 \quad 1.02-2.46$

0.041

$<0.001 \quad 2.20 \quad 1.44-3.38$

$<0.001$

0.001 
sports Austria

Majority of the 240

$34.6 \quad 2.25$

$1.72-2.95$

$<0.001$

2.49

$1.88-3.29$

$<0.001$

days après-ski

during winter

sports Austria

Travelled abroad

to Spain

282

$24.1 \quad 1.33 \quad 1.00-1.75$

$\mathbf{0 . 0 4 7} 1.41 \quad 1.06-1.87$

0.019

Celebrating

carnival

Did not celebrate

$4,725 \quad 17.9 \quad-$

$<0.001$

0.088

carnival (ref.)

Celebrated less

$1,373 \quad 19.0 \quad 1.07$

$0.92-1.25$

$0.369 \quad 1.09 \quad 0.93-1.27$

0.310

than or 3 hours

inside

Celebrated

between 3 and 8

$1,288 \quad 19.4 \quad 1.10$

$0.94-1.29$

$0.228 \quad 1.08 \quad 0.92-1.28$

0.329

hours inside

Celebrated

1,422

$21.7 \quad 1.27$

$1.10-1.47$

$0.001 \quad 1.19 \quad 1.02-1.40$

0.026

between 8 and 18

hours inside

Celebrated more

1,193

23.5

1.40

$1.20-1.63$

$<0.001 \quad 1.24 \quad 1.04-1.47$

0.016 than 18 hours inside

Specific activities

February-March

2020

\begin{tabular}{|c|c|c|c|c|c|c|}
\hline Singing activities ${ }^{a}$ & 389 & 28.8 & 1.71 & $1.37-2.15$ & $<0.001$ & 1.65 \\
\hline
\end{tabular}

$\begin{array}{lllllllll}\text { Attended funeral } & 504 & 23.2 & 1.27 & 1.02-1.57 & \mathbf{0 . 0 3 0} & \mathbf{1 . 0 8} & 0.86-1.35 & 0.494\end{array}$

$\begin{array}{lllllllll}\text { Played wind } & 164 & 27.4 & 1.58 & 1.12-2.23 & \mathbf{0 . 0 1 0} & \mathbf{1 . 2 6} & \mathbf{0 . 8 8}-1.81 & 0.210\end{array}$

instrument in

interplay

$\begin{array}{lllllllll}\text { Visited sport event } \quad 323 & 26.0 & 1.47 & 1.14-1.90 & \mathbf{0 . 0 0 3} & 1.18 & 0.90-1.55 & 0.234\end{array}$

(except soccer

game)

Practiced

gymnastics

Practiced ball sports (except

soccer)

Visited a bar or café

Visited a club or disco
110

$27.3 \quad 1.56 \quad 1.02-2.38$

0.039

1.22

$0.78-1.90$

0.379

174

$36.2 \quad 2.39$

$1.75-3.27$

$<0.001$

1.90

$1.36-2.65$

$<0.001$

$\begin{array}{llll}1,657 & 23.4 & 1.33 & 1.17-1.51\end{array}$

$<0.001$

1.13

$0.96-1.32$

0.145

$294 \quad 26.2 \quad 1.49$

$1.14-1.94$

0.003

1.23

0.90-1.66

0.189 


\begin{tabular}{lllllllll} 
Went out for dinner & 2,294 & 22.0 & 1.23 & $1.09-1.37$ & $<0.001$ & 1.03 & $0.89-1.19$ & 0.691 \\
$\begin{array}{l}\text { Took a day trip } \\
\text { with bus or boat }\end{array}$ & 50 & 34.0 & 2.14 & $1.19-3.85$ & $\mathbf{0 . 0 1 1}$ & 1.78 & $0.97-3.27$ & 0.064 \\
\hline
\end{tabular}

\section{Constant}

0.09

0.000

*P-values $<0.05$ are shown in bold.

Note.- $\mathrm{Cl}$, confidence intervals; OR, odds ratio; Ref., reference category; SARS-CoV-2, Severe Acute Respiratory Syndrome Coronavirus-2; SP, seroprevalence.

a Being member of a choral society, (church)choir or participating in singing activity in February-March 2020.

Multivariable logistic regression model is additionally corrected for age, gender, level of education and geographical region. Overall Cox $\mathrm{R}^{2}$ of the multivariate model was 0.032 .

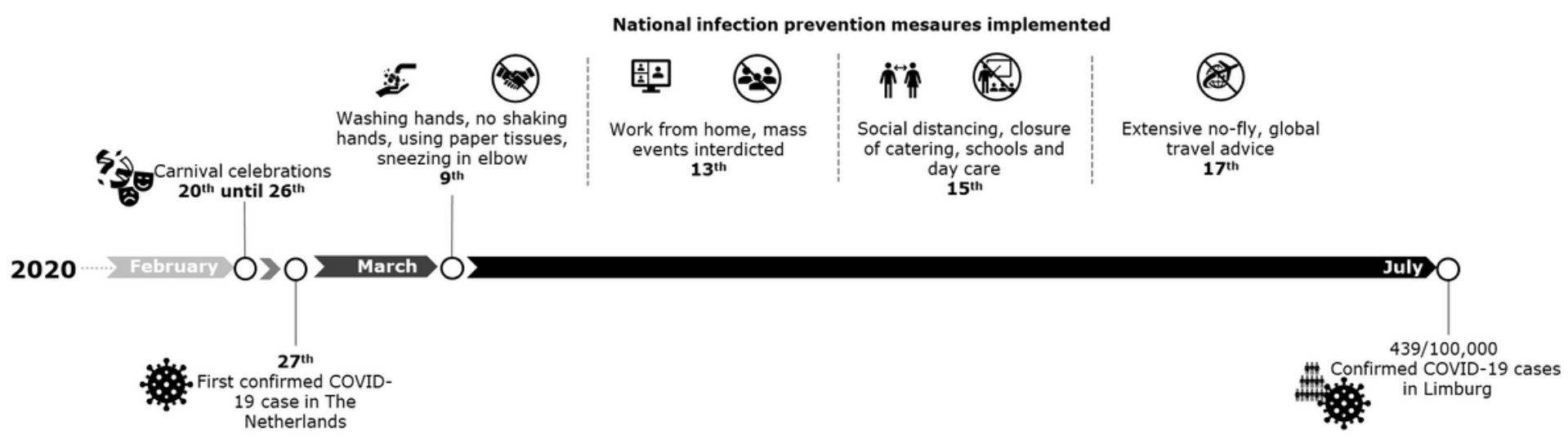

\section{Figure 1}

Timeline depicting events, first COVID-19 case, implementation of prevention measures and cumulative confirmed COVID-19 cases 


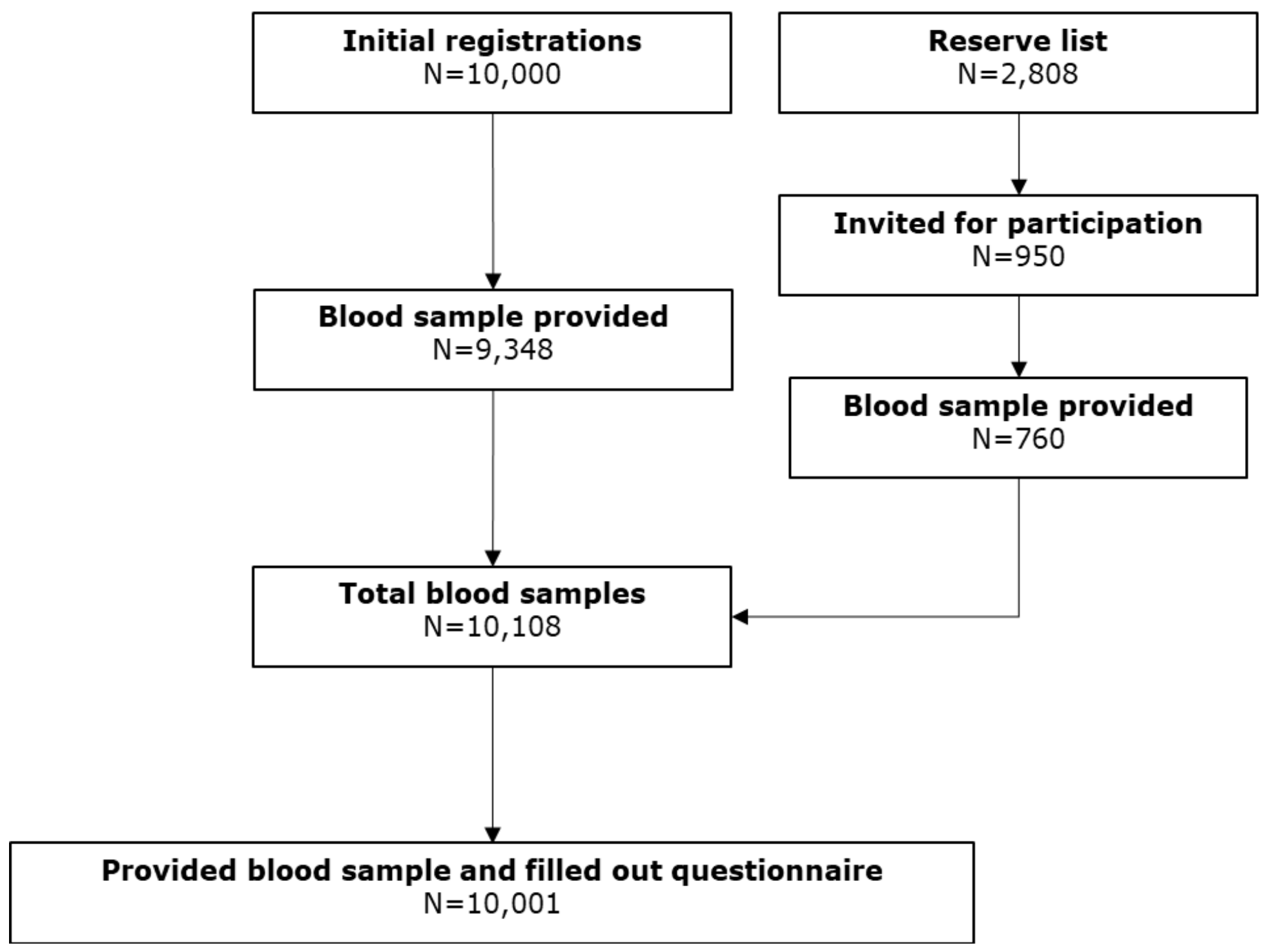

Figure 2

Flow chart of total study population $(n=10,001)$ stratified for initial registrations and reserve registrations 